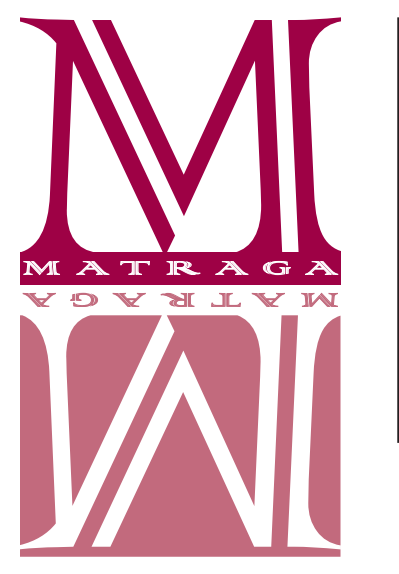

\title{
A anomalia poética de Silvina Rodrigues Lopes
}

\author{
Natália Barcelos Natalino \\ UERJ \\ https://orcid.org/0000-0002-1191-0478
}

$\mathrm{Q}$

uase quinze anos separam as edições portuguesa e brasileira de A anomalia poética, título de Silvina Rodrigues Lopes: a portuguesa, de 2005; a brasileira, de 2019. Outro título de sua extensa obra começou a circular por aqui em 2012, quando a Chão da Feira, editora belo-horizontina, reparou, em parte, esta lacuna editorial: trata-se da primeira e única edição brasileira de Literatura, defesa de atrito, atualmente esgotada. A Chão da Feira vem realizando, nos últimos anos, um esforço notável neste sentido ${ }^{1}$ : a parceria da editora com a Prefeitura de Belo Horizonte e a Embaixada Portuguesa no Brasil vem possibilitando que alguns títulos portugueses sejam, finalmente, viabilizados em terras brasileiras - outros portugueses, como Daniel Faria, Gonçalo M. Tavares, Maria Filomena Molder e Raul Brandão, também já foram publicados pela editora.

Professora universitária, crítica literária, ficcionista, poeta, tradutora e editora, Silvina Rodrigues Lopes faz parte de uma tradição de portugueses que encontra no ensaio o investimento na palavra. Mesmo que de modo mais latente, percebe-se, nos escritos que compõem $A$ anomalia poética - sobretudo naqueles que investem em perspectivas e concepções do literário -, uma problemática que se arrasta desde sua celebrada tese de doutorado, defendida em 1993 e publicada em 1994, na qual a autora se debruça nas inúmeras instâncias e processos de legitimação da (em) literatura, considerando elementos que perturbam a sua própria ambiguidade constitutiva. Lopes diagnostica diversos fatores constituintes do que ela entende como "processo legitimador e fundador da instituição literária”, dentre os quais, a formação teórica, a crítica literária, a opinião pública, os direitos de autor e a integração da disciplina de literatura no sistema escolar (LOPES, 1994). Todos esses mecanismos de circunscrição da literatura parecem ainda estar em jogo em A anomalia poética.

\footnotetext{
1 Notemos, ainda, os esforços da Lumme Editora, que também em 2012 lançou A estranheza-em-comum. 0 livro reúne três ensaios de Silvina Rodrigues Lopes.
}

Ao citar esta resenha, referenciar como: NATALINO, Natália Barcelos. 
Composto por 11 ensaios, originalmente publicados ou apresentados em momentos e meios distintos, o livro é dividido em três seções: I. Ficção e testemunho; II. O artifício, a técnica; e III. Valor. Nos deteremos, nesta resenha, nos ensaios da primeira seção e no ensaio que dá título ao livro. O primeiro deles, "Literatura e circunstância", foi originalmente publicado em 2003 na revista Scripta, coincidentemente também de Belo Horizonte. Apoiada na conviç̧ão de que há certas circunstâncias que interferem no sentido da singularização, o que implica, ainda, uma noção de universalização, Lopes nos mostra que, caso consideremos a ficcionalidade como parte do literário, a tendência é que a vinculemos à universalidade, passando, desse modo, a ignorarmos a singularidade das circunstâncias. Por conseguinte, a ensaísta defende que, na medida em que a linguagem-mundo (mais real, menos ficcional) se impõe, um discurso questionador e construtivo - logo, pensante - se afirma. Como ela própria anota: "Não se trata de recusar a dimensão institucional da literatura, mas de não deixar que ela prevaleça no jogo de forças em que as obras são produzidas e recebidas. [...] Sob a designação 'literatura' não só se inclui uma multiplicidade como um movimento desencadeador do múltiplo" (p. 13). E é também nesse mesmo ensaio que Silvina Rodrigues Lopes já começa a revelar, de antemão, suas principais recorrências teóricas - Gilles Deleuze, Jacques Derrida, Jean-Luc Nancy, Jean-François Lyotard e Maurice Blanchot, por exemplo -, presentes também nos ensaios seguintes.

"A literatura no limite da ficção", segundo ensaio, alude a uma questão há muito discutida e que parece não se esgotar: o problema da relação entre literatura e ficção. Considerando que, hoje, "a própria oposição entre história e ficção foi posta em causa" (p. 34), Lopes entende que, mesmo assim, é a ficção - enquanto pura construção de sentidos possíveis - que invade todos os domínios da (nossa) existência. São muitos os nós da questão, e por isso ela procura esclarecê-los organizando o seguinte percurso: 1) recorre ao pensamento ocidental, passando pela reformulação da noção de verossimilhança, para evidenciar uma contradição: a desvalorização da capacidade de invenção literária; 2) esclarece que, enquanto condição de todo o discurso, a ficcionalidade expõe a falha da ficção enquanto puro artifício; e 3) pensa como a figuração na literatura pode servir como experiência dos limites da ficção. Antes, esclarece: "O facto de a problemática da ficção constituir hoje um aspecto central da teoria literária, o qual interfere com uma série de questões - como a do autor, do leitor, da recepção - que tradicionalmente fazem parte do campo da teoria e que se vêem afectadas por este nó de convergência, que é ao mesmo tempo o lugar das mais vivas divergências" (p. 48).

Em relação aos aspectos que dizem respeito à relação entre ficção e realidade, a ensaísta considera as contribuições de dois autores: Nelson Goodman, que abala a distinção entre mundo real e mundos irreais, ao propor a construção de versões do mundo ou de mundos, considerando que "há tantas versões do mundo quantas as representações que existirem dele, decorrente de uma percepção que varia com o contexto e as circunstâncias" (p. 50); Goodman sublinha, ainda, que a distinção a fazer não é exatamente entre realidade e ficção, mas entre não-ficção e ficção; e Käte Hamburguer, que estabelece uma diferença entre fingimento e ficção, não opondo ficção à realidade, mas sim a enunciado ou enunciado de realidade.

Trata-se, portanto, de "sempre actualizar oposições do tipo natureza/ artifício, mundo real/ mundo ficcional, activo/ passivo, as quais têm por base uma concepção da linguagem, enquanto 
instrumento de representação e comunicação que se auto-anula para dar lugar ao outro - as imagens das coisas, a força do agir” (p. 52). Eis o interesse de Silvina Rodrigues Lopes: a abertura, tensão ou movimento da linguagem para o exterior, de modo que o leitor reinvente a linguagem da obra no confronto com os limites da sua própria linguagem - já que, segundo Lopes, "a leitura é também ela uma experiência que implica a ficcionalidade da linguagem" (p. 59). Logo, "Não se trata de estabelecer uma oposição ou um dilema entre ambas, mas de conceber a travessia da primeira como condição da segunda" (p. 56).

Partindo de uma epígrafe de Friedrich Nietzsche em Humano, demasiado humano, Lopes inicia o terceiro ensaio, "Da necessidade à intranquilidade", dizendo sobre como o termo "humanidade" carrega, ainda hoje - lembremos que o ensaio foi publicado pela primeira vez em 1999 -, um sentido preciso e, ao mesmo tempo, vago, para chegar à questão de um "devir-outro": para ela, o homem "foi superando uma fragilidade original face ao exterior" (p. 61), um processo que se tornou evidência por conta de uma capacidade de tornar indissociáveis a consciência da mortalidade e o desejo de encontro; em suas palavras: "capacidade de dizer 'sim', sem ignorar que é a afirmação que introduz o tempo pelo qual quem afirma é já outro" (p. 62).

A impossibilidade do devir-outro decorre da liquidação do humano - seja pelo terror, seja por meio de um outro tipo de compulsão ao silêncio. Admite, portanto, que o "terror" assombra ainda hoje o nosso cotidiano, e é isso que lhe importa saber: perceber como ele, o terror, surge a partir de uma configuração política e social, que, embora, em larga medida o ignore, "pois ele [o terror] não toma a forma habitual de ameaça mortal pura e simples, mas de morte daquilo que em nós é irredutível a automatismos ou se baseia em regularidades biológicas” (p. 62). Reconhece, no entanto, que não seria possível falar de terror apenas em sentido absoluto - "ele tem, para além disso, o sentido de uma emoção, íntima e social” (p. 63). Ainda, a ensaísta chama a atenção para os diferentes modos de imbecilização que nos cercam (a beleza, a força, o dinheiro), o que colabora para o "reforço do egocentrismo" (p. 70). Como se não bastasse necessitarmos cada vez de mais estímulos, caímos num estado de frustração, caímos na monotonia, como se nos esquecêssemos de que "todos os objetos são monótonos, porque são formas apenas finitas" (p. 70). Daí não conseguirmos mais ficarmos sós, logo, "a possibilidade do encontro desaparece perante a universalização de uma interacção de permanência" (p. 71). Diz, por fim, que numa hipótese catastrofista, caminharíamos para a perda do humano, do relacional - um tempo em que não haveria, tampouco, o terror enquanto emoção. E somente assim, da necessidade à intranquilidade, por meio desse desvio, nos afirma(ría)mos mortais.

São muitas as questões que se colocam nas páginas seguintes de $A$ anomalia poética, partindo desde as relações de estilo, gênero e exemplaridade, passando pela noção de hipertexto, pelas categorias de sujeito-objeto, pela dominação da indústria cultural, chegando até as discussões que põem em xeque os campos da arte e da política - considerando discussões sobre consumo, desejo e os modos como as sociedades acolhem as obras de arte, por exemplo. Em todas essas questões Silvina Rodrigues Lopes procura indagar não só os seus funcionamentos, como também os problemas que os cercam, sempre se propondo a assinalar alguns traços característicos das transformações pelas quais passaram tais noções ou discussões. 
Avançando um pouco mais, é em "A anomalia poética", ensaio que dá título ao livro - não sem razão -, que Silvina Rodrigues Lopes assume, de vez, sua postura interrogatória e, em certa medida, conflituosa e combativa: Lopes (se) interroga sobre "uma obsessiva vontade de classificação" (p. 165) que, segundo ela, se reflete, ainda hoje, em grande parte do discurso sobre poesia; uma tendência que, de acordo com o texto, serve a uma lógica de "promoção das poéticas" (p. 165), similar às técnicas do marketing - prática que reduz o poema a um mero objeto de consumo. Desse modo, o objeto-livro fica refém das críticas dos chamados "sacerdotes da poesia", e não da relação que ele possa estabelecer diretamente com o leitor - uma poesia que se leria "sem a ajuda de especialistas" (p. 170). Daí, sua tese: "Um poema não é um objecto como os outros: não é um objecto; nunca é como os outros. É essa a sua, a nossa, anomalia poética” (p. 166). É essa resistência, esse embate com uma lógica mercantilista, que interessa a Silvina - não só esse embate, mas outros também, e o principal: o embate com o indizível. Esclarece, como aquela que segue defendendo a defesa do atrito, aquela que advoga o duelo:

O duelo com o indizível só cada um o pode travar. Ele tanto se pode dar no mais realista (entendendo que este adjetivo se refere ao verosímil, à existência de referência ao quotidiano) como no menos realista dos poemas. O duelo é sempre com o real; é este, enquanto indizível, que resiste em ato ao instituído, à realidade, e impede que esta se feche, impede que esteja tudo dito. Sabe-se, entende-se, que o duelo é necessário, que não se pode fazer das linguagens fortalezas incólumes à intensidade dos corpos que as constroem e habitam (a sensação de que está tudo dito é talvez a mais mortífera). (LOPES, 2019, p. 169-171)

Consciente de que nem tudo está dito, os escritos de Silvina Rodrigues Lopes direcionam seu olhar não só para os estudos de teoria da literatura e os estudos de literatura portuguesa, como também inclinam seu pensamento para a arte, acumulando conhecimentos teóricos e filosóficos - sempre na tentativa de se inscrever enquanto escreve; a forma ensaística, portanto. Embora nem mesmo as editoras portuguesas tenham realizado, até hoje, o trabalho de corporizar uma edição sistemática, rigorosa e acessível de toda a sua obra crítica, estamos, por ora, bem servidos com a edição brasileira de $A$ anomalia poética, publicação que certamente já vem contribuindo para os estudos no campo da literatura. Torçamos para que, a curto prazo, ações de incentivo, apoio e distribuição possibilitem avanços como este, afinal, sua obra merece ser publicada, debatida e conhecida no Brasil como uma referência indispensável aos campos do comparativismo cultural, da teoria da literatura e seus trânsitos nos tempos de agora - um "agora" que, talvez, nem mesmo Silvina Rodrigues Lopes imaginasse, quando da preparação dos ensaios, ser ainda um sintoma do presente.

\section{REFERÊNCIAS}

LOPES, Silvina Rodrigues. A legitimação em literatura. Lisboa: Edições Cosmos, 1994.

LOPES, Silvina Rodrigues. A anomalia poética. Belo Horizonte: Chão da Feira, 2019. 